\title{
DISCURSO DE POSSE
}

\section{ESPAÇO DO DIREITO NA UFPR*}

\section{Ricardo Marcelo Fonseca**}

Diretor da Faculdade de Direito da UFPR

Magnífico Reitor da Universidade Federal do Paraná, Prof. Dr. Zaki Akel Sobrinho, em nome de quem cumprimento todas as autoridades acadêmicas aqui presentes, Vice-Reitor, ex-reitor, Pró-Reitoras e Pró-Reitores, Diretores de Setor.

Excelentíssimas autoridades institucionais, representante do Tribunal de Justiça, representante da seccional da $\mathrm{OAB} / \mathrm{PR}$, procuradores, advogados, magistrados, que eu cumprimento na pessoa do Desembargador do Trabalho, Dr. Arion Mazurkevic.

Caríssima vice-diretora - e vice-diretora eleita da faculdade de Direito da UFPR - Professora Dr. ${ }^{\text {a }}$ Vera Karam de Chueiri.

Ilustríssimo coordenador do programa de pós-graduação em direito da UFPR, Prof. Dr. Titular José Antônio Peres Gediel.

Ilustríssima representante do Centro Acadêmico Hugo Simas, acadêmica Mariana Santos.

Caríssimos professores e colegas aqui presentes, que eu cumprimento na pessoa de dois amigos, os professores Luis Fernando Lopes Pereira e meu professor de história e de vida, Emérito de nossa UFPR, Professor Dr. Jayme Cardoso.

Caríssimos servidores técnicos administrativos da faculdade, que eu igualmente cumprimento na pessoa da secretária do Setor, Jane Kiatkoski.

Caríssimos estudantes, da graduação e da pós-graduação, desta Casa.

Caros familiares, queridos amigos aqui presentes.

Senhoras e senhores.

Hoje é um dia em que se encerra um ciclo e se inicia outro. Há quatro anos, após um processo eleitoral disputado, neste mesmo Salão Nobre, eu tomava posse na direção da Faculdade de Direito e, no discurso de posse, tomava como eixo condutor da minha fala o tempo. Tempo que nos envolve a todos, tempo da tradição da Faculdade de Direito - centenária como é nossa Universidade - e a necessidade da instauração de

* Discurso de posse do Diretor da Faculdade de Direito da UFPR, do quadriênio 2012-2016.

** Professor da Faculdade de Direito da UFPR. E-mail: ricardomarcelo04@yahoo.com.br 
um tempo de paz e solidariedade institucional, de um tempo da superação, de um tempo de transformação.

Agora, quatro anos depois, tendo decorrido um tempo intenso e frutífero, peço licença a todos para me servir de outra imagem - que é real e palpável, mas também é metafórica - para me conduzir nesta fala que abre uma nova gestão: o espaço.

Espaço que é físico, forte e austero - como se percebe nas escadarias, diante da colunata deste Prédio Histórico da Universidade do Paraná, símbolo da cidade de Curitiba e morada da excelência do saber jurídico paranaense, nacional e internacional. Mas também espaço que é simbólico, que acolhe gerações ilustres de antepassados, de personalidades acadêmicas e políticas que orgulharam a universidade e a sociedade paranaense. Espaço que constitui o lugar de referência não só simbólica, mas também existencial para tantos professores e tantos servidores técnicos que aqui já escreveram e ainda escrevem sua história, para tantos estudantes.

Mas além de físico e simbólico, o espaço pode ser tantas outras coisas e ter tantas outras dimensões. Mesmo no âmbito do direito, o mestre Paolo Grossi dizia, ao analisar a Ordem Jurídica Medieval, da importância da noção de pertencimento para experiência normativa, sobre a centralidade da terra, que era "fonte de vida e garantia de sobrevivência, portadora em si de regras originárias e perfeitamente legíveis" Noutro registro - o da poesia - Fernando Pessoa, colocando o espaço como parâmetro existencial, dizia que "A vida é para nós o que concebemos dela. Para o Rústico cujo campo lhe é tudo, esse campo é um império. Para o Cesar cujo império ainda é pouco, esse império é um campo".

E ainda como nos mostra a prosa literária de Ítalo Calvino, no relato de Marco Pólo a Kublai Khan sobre as inúmeras cidades do império tártaro (as cidades invisíveis, todas com nomes de mulher), as cidades, além de lugar, também podem ser desejo, também podem ser o receptáculo da memória, dos sinais, dos olhares, das trocas. Afinal, o viajante sente desejo de uma cidade até encontrar Isidora, onde se misturam desejos e recordações. Ao visitar Zora, percebe-se que sua propriedade é a de permanecer na memória do visitante. E a impressão que se tem da cidade de Despina depende do olhar de quem a alcança: se do cameleiro, se se chega pelo deserto, ou se do marinheiro, se se chega pelo mar.

O espaço é muito mais que o lugar: é também o simbólico, contém e contempla memórias, desejos, perspectivas e reconhecimentos. E se assim é, o espaço nessa fala é o fio condutor perfeito para me permitir abordar algumas necessárias perspectivas.

Por primeiro, é necessário falar do espaço desta Faculdade, espaço que tanto nos ocupa e que tanto nos orgulha. Espaço que precisa de luta cotidiana para afirmação de

1 GROSSI, Paolo. L'ordine giuridico medievale. Roma/Bari: Laterza, 1995, p. 74. 
sua racionalidade pública; espaço que deve ser de solidariedade e de respeito ao mesmo tempo que de dissenso e de aceitação da pluralidade, no desafio cotidiano, que é radicalmente democrático, em encontrar a unidade na diversidade; espaço que deve ser ao mesmo tempo da igualdade e do mérito.

Neste espaço, nesses últimos tempos, creio que logramos pavimentar avenidas, como nos dispúnhamos a fazer quatro anos atrás, mirando um horizonte de ensino, pesquisa e extensão de excelência: logramos instituir um novo projeto político pedagógico, moderno, atualizado e flexível, aberto às novas demandas do saber jurídico e à velocidade do devir do direito; um currículo que aproxima ensino e pesquisa (sobretudo nas disciplinas tópicas) e os articula com a extensão para realizar a vocação de um ensino socialmente comprometido (como cabe a uma universidade pública) mas sem ser assistencialista; a partir daí, procedemos a uma total reformulação - e creio podermos dizer, uma refundação - do Núcleo de Prática Jurídica, que é hoje uma verdadeira usina da extensão, e é dotado de estrutura administrativa permanente, que tem seis professores titulados (no processo de contratação da sétima) e que em breve também terá autonomia política interna. A prática jurídica (engajada com interesses jurídicos dos que são social e economicamente mais vulneráveis) passou a ter um papel inédito na formação dos nossos estudantes. Tudo isso faz com que nossa faculdade siga aumentando seu papel de absoluta liderança nos testes unificados nacionais da $\mathrm{OAB}$, nos concursos públicos das áreas jurídicas e em todos os indicadores que demonstram a efetiva preparação de nossos egressos para o mercado. Mas fazemos isso sem renunciar a um perfil que embora não ignore o mercado, não existe em função dele, um perfil de educação jurídica que não renuncia a ser sobretudo acadêmica e responsável pela produção e reprodução de conhecimento de qualidade que também seja capaz de inserção social comprometida.

Mais: contratamos, ao longo desses quatro anos, vinte e sete novos professores, o que representou o aumento de quase $50 \%$ do nosso corpo docente permanente de quatro anos atrás. Com isso, a partir de 2012, realizamos a divisão das turmas (do primeiro ao terceiro anos), atendendo antiga e histórica reivindicação estudantil. Procedemos ainda a uma reestruturação crucial no âmbito da atuação dos técnicos administrativos, que resultou num inquestionável acréscimo de eficiência, mercê da dedicação e do compromisso dos nossos atuais servidores aqui lotados. Renovamos do ponto de vista físico a Faculdade: temos hoje salas de aula com equipamentos multimídia, com renovação radical das carteiras dos estudantes e até mesmo com ar condicionado; hoje nossos espaços não têm a aparência do abandono típico de lugares públicos descuidados. E nesse exato momento, no terceiro andar deste prédio, há um significativo espaço agora em fase de projetos e avaliações (e que nos estarão disponíveis no início de 2013) que desafogarão um pouco nossas demandas físicas.

Mas mais do que tudo isso, nesses últimos quatro anos este espaço se renovou em realizações que não são físicas, mas que nem por isso não são menos importantes. 
O rol dos grandes nomes acadêmicos - nacionais e estrangeiros - que por aqui passaram nunca foi tão expressivo. Nossa internacionalização das relações acadêmicas (internacionalização de qualidade!) nunca atingiu os níveis que agora temos: nestes quatro anos houve simplesmente QUATRO cursos do Edital da Escola de Altos Estudos da CAPES (edital específico que só contempla pólos de excelência na pesquisa e que só nós realizamos em toda a UFPR e só nós realizamos em toda a área de direito no Brasil). E agora, ainda nesta semana, após longa negociação, será concretizada a instauração de um doutorado em cotutela, para dupla titulação, entre nosso programa de pósgraduação em direito e o dottorado di ricerca in giurisprudenza da Università degli Studi di Firenze.

$\mathrm{E}$ ainda mais do que isso (para nos mantermos nas renovações não visíveis dos últimos quatro anos): hoje a Faculdade de Direito vive um clima de paz institucional, de reforço das solidariedades acadêmicas, de esforço contínuo para estabelecimento de um bom ambiente de trabalho e de produção científica, colocando as naturais divergências na cena pública do debate e da deliberação, sem segredos e sem conspirações. Houve um resgate do respeito à autonomia dos colegiados e das plenárias departamentais que nestes quatro anos jamais - repito jamais - assistiram a um confronto desnecessário por parte da Direção e da Vice-Direção. As relações institucionais foram reconectadas, com diálogo, com respeito, com democracia.

Certamente foi isso que fez com que nossa comunidade tenha nos sufragado uma votação tão generosa neste último processo de escolha para a Direção e Vice-Direção da Faculdade, malgrado tenhamos sido candidatos únicos e apesar de estarmos em contexto de greve. Votação que muito nos orgulha, mas que também nos enche de responsabilidades para o futuro.

E a gestão do nosso espaço acadêmico, se feito de modo plural, com racionalidade pública e com desejo de transformação, não é de nenhum modo tarefa simples. Para quem é gestor, acadêmico ou não, administrar a tensão natural entre a dimensão instituída e a dimensão instituinte é um permanente desafio. No nosso caso, manter toda a estrutura administrativa e acadêmica que herdamos em bom funcionamento - como creio que logramos fazer - e ao mesmo tempo apontar para mudanças estruturais neste espaço, e depois, ser capaz de geri-las, é tarefa de grande envergadura. Mas estamos aceitando, com a ajuda de nossa comunidade, este novo desafio e as grandes responsabilidades que daí decorrem.

Grandes responsabilidades porque efetivamente há muita coisa a ser ainda terminada e consolidada: nossa transição curricular, nosso novo modelo de prática jurídica, o aumento da eficiência administrativa, o aumento espacial e de acervo de nossa biblioteca, a crescente institucionalização de nossa cultura democrática.

Mas nesse novo desafio que aceitamos, prosseguiremos em outra das convicções que sustentávamos há quatro anos e que creio que levamos adiante neste mandato que 
se encerra: a efetiva inserção do nosso Setor de Ciências Jurídicas na Universidade. Ficou definitivamente para trás a imagem de que este espaço, aqui na Praça Santos Andrade, como uma ilha dentro de nossa academia. O Direito hoje ouve todas as vozes da Universidade, mas também quer ser ouvido. O Direito hoje acredita firmemente no diálogo acadêmico com outras áreas e no diálogo respeitoso no plano político institucional. Creio, de fato, ter havido uma mudança sensível na relação do Direito com os outros setores da Universidade, bem como com seus órgãos e unidades administrativos.

E neste passo, é imperioso para mim fazer o registro de reconhecimento ao atual Reitor da Universidade, na gestão que também se encerra neste ano de 2012 , Prof. Dr. Zaki Akel Sobrinho, pelo diálogo que encetou com a nossa Faculdade de Direito e pelo apoio que nos foi dado. Nele tive um gestor atento à voz da Faculdade do Direito, mesmo quando a voz era de reclamação minha sobre algum problema de sua gestão. No plano das relações administrativas com o Setor de Ciências Jurídicas, devo reconhecer publicamente, por razões de justiça, que houve sensibilidade e sobretudo houve consideração institucional, que se traduziu inclusive na presença frequente do nosso gestor máximo aqui em nossa Faculdade. Se alguém pode dizer, não sem certa razão, que é obrigação comezinha do nosso Reitor ter atenção, sensibilidade e presença na relação com os setores que compõem a Universidade, não é menos verdadeiro que nós, aqui no Direito, não havíamos recebido, ao menos num passado recente, a atenção que merecíamos por parte dos dirigentes máximos. Por isso, professor Zaki, registro meu agradecimento.

Mas agora outro ciclo se inaugura. E ainda há muitas demandas e muitos debates para o futuro que nossa Faculdade deverá se inserir, dentro do debate da Universidade, de modo resoluto.

Antes de tudo a questão do espaço físico deste Prédio Histórico, que inevitavelmente vai se abrir com a saída do curso de psicologia ainda neste ano, mas também pela saída de outras pró-reitorias mais adiante. Como habitantes desde a fundação deste prédio, que hoje é monumento e símbolo da cidade, acreditamos ter o direito de discutirmos desde o princípio os critérios de ocupação destes espaços e as suas condições. Nossa radicação aqui - que já é quase centenária - é premissa deste debate. Certamente acreditamos que a Universidade deve possuir e seguir um seu plano diretor coerente, mas também acreditamos que mesmo nas discussões com perfil técnico é necessário ter lugar para um debate efetivamente democrático no qual os efetivos atores desta universidade - que produzem pesquisa, ensino e extensão devem estar incluídos. Seremos avessos, por isso, à eventuais futuras soluções ou propostas tecnocráticas que venham ignorar as nossas conhecidas especificidades e as imensas demandas que nosso curso tem do ponto de vista da ocupação dos espaços. Entendemos que as análises técnicas, como meios que são, devem servir à nossa atividade fim, e nunca o contrário. Queremos debater concepções, necessidades e 
condições de habitação e segurança neste espaço. E buscaremos, após este diálogo com os órgãos e colegiados competentes neste debate, fazer nossa lição de casa: promover um debate interno capilarizado e profundo, mas equilibrado e com bom senso, para construirmos juntos um projeto de futuro para este espaço.

E deixo claro que, quanto a esse particular, não queremos mais do que precisamos. Somos e sempre seremos contra a ocupação irracional dos espaços - pois esta ociosidade certamente é contrária à racionalidade pública. Mas hoje precisamos muito de expansão (para ainda além daquela agora em curso no terceiro andar), não só pelo crescimento decorrente do REUNI (que se completará somente no ano que vem), como também pelo radical crescimento no plano docente e, sobretudo, pelo exponencial crescimento de projetos e iniciativas (tanto nos planos do ensino, da pesquisa, quanto da extensão) que advieram com a mudança de nosso projeto pedagógico. Hoje somos um pé tamanho 43 num sapato tamanho 37 .

Um segundo debate que não renunciaremos a participar - que hoje já está sempre presente em nossos conselhos, colegiados, centros acadêmicos e também nas esferas de representação sindical - diz respeito ao incremento e ao estatuto da democracia dentro de nossa universidade. Este debate se mostra urgente porque os critérios de nossa democracia parecem estar permanentemente na pauta da nossa Universidade - o que em si mesmo é positivo - mas ao mesmo tempo isso parece ocorrer de um modo que produz alguns efeitos que nossa comunidade deve estar ao mesmo tempo atenta: quero dizer que, a meu ver, o debate sobre a democracia institucional em nossa comunidade muitas vezes parece constituir-se de modo excessivamente linear, diluindo a noção substancial de participação na ideia instrumental de representação. O problema é que nesse movimento (considerado por tantos automático e óbvio) são deixados de lado os frequentes problemas do deficit democrático causado pelo corporativismo crescente de várias instâncias representativas e que, em verdade, autonomizam seus interesses em relação à base que supostamente deveriam espelhar. Com isso quero dizer apenas que incrementar a democracia na Universidade implica incrementar com critérios substanciais, e não meramente formais, a participação dos mais diversos sujeitos nas esferas de decisão. Estando cientes das especificidades de uma academia que tem como referência o conhecimento de qualidade (e que na produção, reprodução e inserção social desse conhecimento, é que encontra seu papel e sua razão de ser diante do mundo que nos cerca), devemos avançar na construção dos mecanismos que aproximem o diálogo entre os que dirigem e os que são dirigidos, bem como os mecanismos de controle destes com relação àqueles. E fazer isso sem maniqueísmos e sem critérios meramente lineares (que são procedimentos avessos a uma entidade pensante e criativa como a Universidade), com vistas a diminuir os focos corporativos que eventualmente podem se tornar elementos de imobilização da Universidade. É necessário democratizar, mas também é necessário racionalizar e qualificar os critérios de discussão e de gestão acadêmica. É necessário 
aumentar a democracia, mas no mesmo compasso aumentar nossa racionalidade acadêmica e diminuir o nosso corporativismo.

E queremos contribuir neste debate na ocasião que agora já está anunciada e se mostra como a mais frutífera e adequada: refiro-me ao processo Estatuinte na Universidade Federal do Paraná, já deflagrado e que amadurecerá no ano que vem. Queremos nos colocar a serviço da Universidade nesta discussão e reverberá-la - inclusive com um novo regimento setorial - na nossa comunidade.

E ao falar novamente da nossa comunidade, completo a parábola e retorno ao nosso espaço da Faculdade de Direito, o qual não pode deixar de ser também, como disse a professora Vera Karam de Chueiri, espaço do reconhecimento. E aqui mais uma vez para falar dessa dimensão de reconhecimento, tomo o socorro de Ítalo Calvino, que num diálogo memorável no qual Marco Polo descrevia a Kublai Khan uma ponte, pedra por pedra, foi ele interrompido pelo Imperador que perguntou ao viajante: "Mas qual é a pedra que sustenta a ponte?", ao que responde Marco: "A ponte não é sustentada por esta ou aquela pedra, mas pela linha do arco que ela forma". Segundo Calvino, Kublai Khan permanece em silêncio e enfim redargúi: "Por que então me fala das pedras? É só o arco que me importa", ao que finalmente Marco Pólo responde: "Sem pedras não existe arco".

Com isso quero expressar nosso reconhecimento público a todos os que, neste espaço da Faculdade de Direito, ao longo destes quatro anos de intenso trabalho, constituíram as imprescindíveis pedras que formaram o arco que manteve de pé esta ponte na direção de uma faculdade para o futuro: ao conjunto dos técnicos administrativos, da secretaria da direção, dos departamentos, da coordenação da graduação e da pósgraduação e do Núcleo de Prática Jurídica; aos chefes de Departamento (e seus suplentes) que, ao darem apoio à gestão, foram decisivos em cada passo que demos; ao professor coordenador de pesquisa da Faculdade durante toda a gestão; à professora e aos professores que levaram à frente a coordenação de extensão neste mandato; à professora que esteve à frente da representação setorial na Assessoria de Relações Internacionais. Às professoras que conduziram o núcleo de monografias. E também aos colegas docentes que nos representaram no CEPE (e também no COPLAD) neste período.

$\mathrm{E}$ devo registrar também, de modo muito especial, agradecimento à professora Maria Cândida Kroetz, que com muita solidariedade e dedicação esteve à frente do Núcleo de Prática Jurídica durante o delicado e intenso período de transição que enfrentamos no passado e continuamos a enfrentar. Como necessariamente devo registrar nosso agradecimento aos coordenadores do nosso programa de pós-graduação, professores José Antônio Peres Gediel e Rodrigo Xavier Leonardo, com quem trabalhamos juntos e dividimos projetos e apreensões nestes quatro anos. Agradecimento também especial aos caríssimos amigos e solidários colegas, que suportaram com bravura e competência as tensões da coordenação do curso - este nervo sensível de 
nossa Faculdade - durante todo este mandato, professores Luis Fernando Lopes Pereira, Rodrigo Kanayama e Clara Borges.

Como se vê, se houver reconhecimento dos méritos por realizações nestes últimos quatro anos, eles devem ser necessariamente coletivos. Nestes novos tempos e neste renovado espaço, uma gestão responsável de nossa Faculdade só ocorre com uma numerosa e comprometida equipe, o que eu e Vera, afortunadamente, compusemos. Estas pedras constituem o verdadeiro arco que compôs nossa ponte.

Finalmente, como nas cidades de Calvino, devo registrar por forçosa justiça o nome das mulheres que, para mim, em vários âmbitos, foram-me e me são tão cruciais quanto as colunas deste prédio: a Vera Karam de Chueiri; a Jane do Rocio Kiatkoski; à Denise Agostini; e à Ângela.

Agora se inicia outra jornada. Para alcançarmos novos espaços e para consolidarmos outros, queremos, como fizemos até aqui, caminhar juntos com nossa comunidade e, nesta travessia, fazer florescer cada vez mais nossa vocação de excelência acadêmica. Já conhecemos as pedras no caminho e com elas não nos intimidaremos. Ao contrário, usaremos os calos que acumulamos até agora para afastar os empecilhos que surgirem.

É que - pela última vez recorrendo a Ítalo Calvino, em suas Cidades Invisíveis acreditamos nas palavras de Marco Pólo, para quem: "o inferno não é algo que será; se ele existe, é o que está aqui (...) Existem dois modos para suportá-lo. O primeiro é cômodo para tantos: aceitar o inferno e tornar-se parte dele até não mais percebê-lo. $O$ segundo é arriscado e exige atenção e aprendizado contínuos: buscar e saber reconhecer quem e o quê, em meio ao inferno, não é inferno, e fazê-lo durar, e dar-lhe espaço".

Tenho convicção que, juntos, a Faculdade de Direito saberá abrir mais e maiores espaços de excelência que todos almejamos e fazê-los durar.

Encerro com a mais pessoal de todas as notas. Há quatro anos, neste mesmo auditório, sentavam-se nas primeiras filas deste Salão Nobre duas figuras para mim centrais que perdi no meio da travessia deste mandato: Clóvis Machado da Silva e Leocádia Meger Fonseca. O primeiro, meu sogro, professor titular desta Universidade, pesquisador 1-A do CNPq, modelo eterno para mim de pesquisador e de gestor acadêmico republicano. A segunda, minha mãe, modelo eterno de doçura e de fé nas pessoas. Que seus exemplos, nas suas qualidades, sirvam-me de inspiração.

Muito obrigado. 